\title{
Implementasi Hypnotherapy dalam Meningkatkan Motivasi
}

\author{
Denok Sunarsi ${ }^{1}$, Ali Maddinsyah ${ }^{2}$, Udin Ahidin $^{3}$, Achmad Setya Roswendi $^{4}$, Dedi Supriadi $^{5}$ \\ Universitas Pamulang ${ }^{1,2,3}$ \\ Sekolah Tinggi Ilmu Kesehatan Jenderal Achmad Yani 4,5 \\ denoksunarsi@unpam.ac.id, alimaddinsyah@unpam.ac.id, dosen00406@unpam.ac.id, \\ achmadsetya1970@gmail.com,chan_dieta@yahoo.com
}

\begin{abstract}
Modern hypnotherapy methods have a greater role to 'open' awareness in knowing the main problem and helping to heal or solve the problem by himself. someone becomes more comfortable with his condition and can accept his condition, so it does not interfere with activities or daily activities. Lack of motivation can reduce self-confidence where every individual, be it an employee, teacher, student, housewife or entertainer desperately needs selfconfidence in all fields. The purpose of this community service is to train the participants in applying hypnosis and hypnotherapy and to change the mindset of the participants towards that knowledge. The method used is the presentation of material through seminars and frequently asked questions and simulations both individually and in groups. The result of devotion is that the participants are able to implement hypnosis and hypnosis for the needs of increased motivation, treatment and self-development both for themselves and to help others who experience constraints of confidence and improve performance. The next activity the community service team will conduct hypnoteaching training for teachers and hypomotivation for students.
\end{abstract}

Keywords: Hypnosis; Hypnotherapy; Motivation.

\begin{abstract}
Abstrak
Metode hypnotherapy modern lebih banyak berperan untuk 'membuka' kesadaran dalam mengetahui masalah utamanya dan membantu untuk menyembuhkan atau menyelesaikan masalahnya oleh dirinya sendiri. seseorang menjadi lebih merasa nyaman dengan kondisinya dan dapat menerima kondisinya, sehingga tidak mengganggu aktivitas atau kegiatan sehari-hari. Kurangnya motivasi dapat menurunkan kepercayaan diri dimana setiap individu, baik itu karyawan, pengajar, pelajar, ibu rumah tangga maupun seorang entertain sangat membutuhkan rasa percaya diri dalam segala bidang. Tujuan dilaksanakannya pengabdian kepada masyarakat ini adalah untuk melatih para peserta dalam mengaplikasikan hypnosis dan hypnotherapy serta mengubah mind set peserta terhadap ilmu tersebut. Metode yang digunakan adalah pemaparan materi melalui seminar dan tanya jawab serta simulasi secara langsung baik secara individual maupun berkelompok. Hasil pengabdian adalah para peserta mampu mengimplementasikan hypnosis dan hypnoterapy untuk kebutuhan peningkatan motivasi, pengobatan dan pengembangandiri baik untuk diri sendiri maupun untuk membantu orang lain yang mengalami kendala percaya diri dan meningkatkan kinerja. Kegiatan selanjutnya tim pengabdian kepada
\end{abstract}


masyarakat akan melakukan pelatihan hypnoteaching untuk para pengajar dan hypnomotivasi untuk para pelajar.

Kata Kunci: Hipnosis; Hipnoterapi; Motivasi.

\section{A. PENDAHULUAN}

Hipnoterapi adalah salah satu cabang ilmu psikologi yang mempelajari manfaat sugesti untuk mengatasi masalah pikiran, perasaan dan perilaku. Hipnoterapi dapat juga dikatakan sebagai suatu teknik terapi pikiran dan penyembuhan yang menggunakan metode hipnotis untuk memberi sugesti atau perintah positif kepada pikiran bawah sadar untuk penyembuhan suatu gangguan psikologis atau untuk mengubah pikiran, perasaan, dan perilaku menjadi lebih baik. Orang yang ahli dalam menggunakan hipnotis untuk terapi disebut "hypnotherapist". Hipnoterapi menggunakan pengaruh kata-kata yang disampaikan dengan teknik - teknik tertentu. Satu-satunya kekuatan dalam hipnoterapi adalah komunikasi. (Kahija YF., 2017).

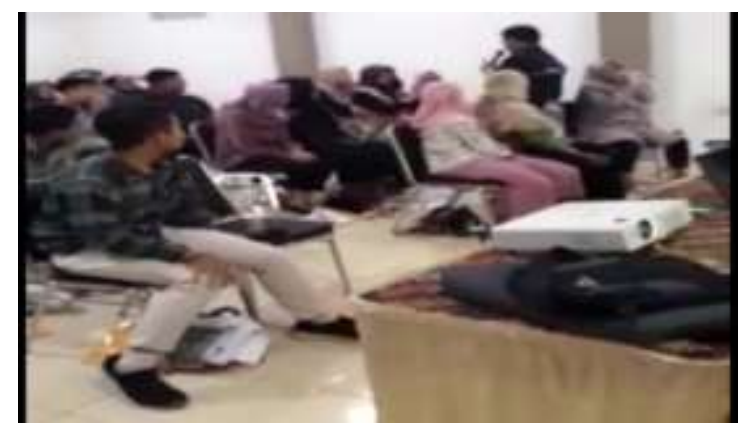

Gambar 1. Penyampaian Materi Teoritis.

Hypnotherapy modern yang dikenal pada hari ini, memiliki orientasi yang sangat berbeda dengan awal kelahirannya di era Mesmer. Pada era tersebut nuansa Hypnotherapy masih sangat authoritarian, alias menonjolkan figur otoritas dari Hypnotherapys. Pada saat itu pemahaman mengenai pikiran bawah sadar manusia masih sangat terbatas, sehingga manusia dipandang sebagai suatu obyek hidup yang dapat diprogram dengan mudahnya.

Identifikasi masalah di lapangan menunjukkan masih banyak karyawan memiliki motivasi kerja yang rendah. Hal itu disebabkan beberapa faktor dalam diri. Seperti:

\section{Kurangnya percaya diri}

Seorang yang tidak memiliki kepercayaan diri takut untuk menerima tantangan yang memaksa mereka keluar dari zona nyaman. Sementara itu seseorang yang percaya diri malah ingin mendapatkan tantangan baru dan keluar dari zona nyaman mereka. Dua tipe orang tersebut bisa ditemukan di lingkungan kantor, yakni pada diri karyawan. tingkat kepercayaan diri karyawan dapat terlihat dari kinerja mereka. Seseorang yang tidak percaya diri akan sulit memberikan hasil pekerjaan terbaiknya.

\section{Cemas}

Bagi sebagian orang, kata "cemas" seperti mencekik dan membuat gelisah. Tak enak makan, susah memejamkan mata kala malam. Ketakutan-ketakutan yang sering tak beralasan. Ide, mimpi, harapan, tak akan hadir kala pikiran manusia selalu diselimuti kecemasan. Seperti air, ketika diaduk dia bertambah keruh. Butuh ketenangan agar air itu memisahkan yang kotor. Hingga bening tercipta.

\section{Opini negatif}

Opini negatif adalah salah satu hal yang menjadi hambatan manusia di dunia ini ketika hendak berlaku maju. Bisa dilihat percakapan disekeliling kita.

\section{Merasa Diri Tidak Penting}

Perasaan tidak penting membuat manusia tak memiliki cita-cita besar. 
Bagaikan satu elemen kecil dalam pesawat terbang, mungkin satu bautnya.

Sebagaimana hipnotis pada umumnya, maka penyajian materi dengan menggunakan metode hypnoteaching dilakukan dengan mengkomunikasikan pikiran alam bawah sadar yang dapat menimbulkan sugesti siswa untuk berkonsentrasi secara optimal terhadap materi yang disampaikan guru. Pikiran alam bawah sadar lebih mendominasi dalam setiap kegiatan manusia.

Pikiran sadar hanya berpengaruh sekitar kurang lebih 12\%, sementara pengaruh pikiran bawah sadar memegang kendali $88 \%$. Pikiran bawah sadar lebih bersifat netral dan sugestif. Pikiran bawah sadar dapat diasumsikan sebagai sebuah memori jangka panjang manusia yang menyimpan berbagai peristiwa, baik yang berdasarkan pengalaman pribadi (eksperimental) maupun orang lain (induksi).

Kondisi hipnotis dapat dibagi menjadi hipnotis ringan (light hypnosis) dan hipnotis dalam (deep hypnosis). Proses belajar mengajar lebih menggunakan teknik light hypnosis. Dalam kondisi hipnotis ringan, gelombang pikir seseorang berada pada light alpha.

Ibnu Hajar (2012) mengemukakan beberapa langkah dasar yang perlu dilakukan dalam mengimplementasikan metode hypnoterapy: (1). Niat dan motivasi dalam diri sendiri. Dalam mengimplementasikan metode ini, seseorang harus menanamkan niat yang kuat, sebab niat ini akan memunculkan motivasi yang tinggi dan komitmen yang kuat. (2). Pacing. Pacing adalah menyamakan posisi, gerak tubuh, bahasa, serta gelombang otak. (3). Leading. Leading berarti memimpin atau mengarahkan sesuatu. Proses ini dilakukan setelah pacing.
(4). Gunakan kata positif. Langkah pendukung selanjutnya adalah menggunakan bahasa atau kata-kata yang positif. Kata-kata positif sesuai dengan sistem kerja pikiran alam bawah sadar yang tidak menerima sugesti negatif. (5). Berikan pujian. Pujian merupakan reward peningkatan harga diri seseorang. Pujian merupakan salah satu cara untuk membentuk konsep diri seseorang. Khususnya ketika ia berhasil melakukan atau mencapai prestasi. Sekecil apapun bentuk prestasinya, tetap berikan pujian, termasuk ketika ia berhasil melakukan perubahan positif pada dirinya sendiri. Dengan pujian, seseorang akan terdorong untuk melakukan yang lebih dari sebelumnya. (6). Modeling. Modeling adalah proses memberi tauladan melalui ucapan dan perilaku yang konsisten. Hal ini sangat perlu dan menjadi salah satu kunci hypnoterapy. Setelah seseorang menjadi nyaman dengan Anda, kemudian dapat Anda arahkan sesuai yang Anda inginkan, dengan modal kalimat-kalimat positif. Maka perlu pula kepercayaan (trust) pada Anda dimantapkan dengan perilaku anda yang konsisten dengan ucapan dan ajaran Anda. Sehingga anda selalu menjadi figur yang dipercaya.

Peserta pengabdian kepada masyarakat ini adalah karyawan dan pelaku bisnis serta pengajar, kurang lebih sebanyak 25 orang yang diadakan di sebuah ruang pertemuan di daerah Cimahi Jawa Barat. Hasil capaian adalah melatih peserta supaya dapat mengimplementasikan hypnosis dan hypnoteraphy dalam kehidupan sehari-hari baik itu dalam dunia kerja maupun daunalam keseharian.

\section{B. PELAKSANAAN DAN METODE}

Metode pengabdian dilaksanakan
dengan metode seminar, diskusi dan


simulasi secara langsung baik perseorangan dan dengan cara berkelompok.

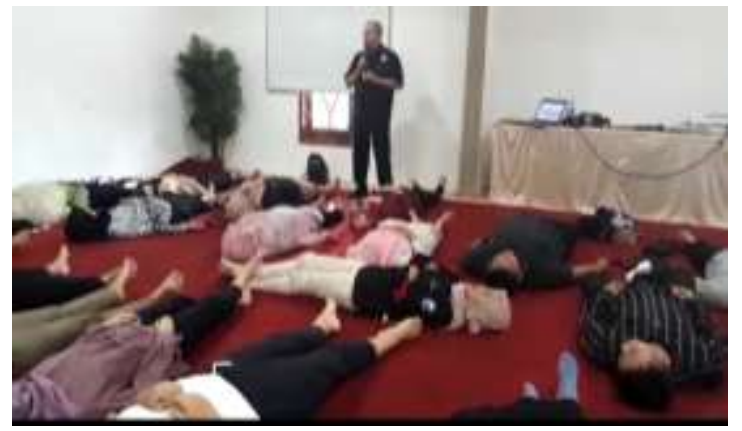

Gambar 2. Aplikasi Hypnosis

Para peserta terdiri dari praktisi kesehatan, guru, dosen dan karyawan. Dalam kegiatan pengabdian ini para peserta diajarkan berbagai teknik menghipnosis dengan sugestibilitas dari dasar atau dengan cara mudah. Peserta dapat merasakan bagaimana terhipnosis untuk menenangkan diri dan menerima sugerti dari peserta lain serta peserta dapat menghipnosis dan memberikan sugesti kepada peserta lainnya. Untuk menunjang kegiatan tim pengabdi menggunakan media powerpoint untuk pemeparan materi, infokus dan sound system.

\section{HASIL DAN PEMBAHASAN}

Secara harfiah, kata Hypnotherapy terdiri dari dua kata, yaitu hypno dari hipnotis dan terapi. Keduanya memiliki makna yang utuh. Hipnotis awalnya dari neuro-hypnotism atau tidurnya sistem saraf. Adapun secara istilah hipnotis adalah suatu keadaan yang muncul secara alami dimana kesadaran seseorang menjadi lebih mudah untuk menerima sugesti dari luar. (Hakim, 2011).

Keadaan hipnotis meningkatkan memori dan persepsi, serta bisa menjadi pemicu penyembuhan, peningkatan kreatifitas dan perbaikan kualitas hidup lainnya. Kemudian terapi adalah pengobatan

(Gunawan, 2012). Jadi jika disimpulkan bahwa Hypnotherapy secara harfiah adalah terapi dengan cara hipnotis. Secara istilah Hypnotherapy adalah terapi yang digunakan atau diterapkan kepada klien dalam keadaan hipnosis. Banyak definisi mengenai Hypnotherapy, karena setiap Hypnotherapys memiliki setidaknya satu definisi. Oleh karena itu Hypnotherapy adalah sebuah terapi yang popoler yang menggunakan hipnotis sebagai alat bantu yang utama. Untuk memahami Hypnosis atau Hypnotherapy secara mudah dan benar, sebelumnya kita harus memahami bahwa aktivitas pikiran manusia secara sederhana dikelompokkan dalam 4 wilayah yang dikenal dengan istilah Brainwave, yaitu: Beta, Alpha, Theta, dan Delta (IBH, 2010).

Beta adalah kondisi pikiran pada saat sesorang sangat aktif dan waspada. Kondisi ini adalah kondisi umum ketika seseorang tengah beraktivitas normal. Frekuensi pikiran pada kondisi ini sekitar $14-24$ Cps (diukur dengan perangkat EEG). Alpha adalah kondisi ketika seseorang tengah fokus pada suatu hal (belajar, mengerjakan suatu kegiatan teknis, menonton televisi), atau pada saat seseorang dalam kondisi relaksasi. Frekuensi pikiran pada kondisi ini sekitar $7-14$ Cps. Theta adalah kondisi relaksasi yang sangat ekstrim, sehingga seakan-akan yang bersangkutan merasa "tertidur", kondisi ini seperti halnya pada saat seseorang melakukan meditasi yang sangat dalam Theta juga gelombang pikiran ketika seseorang tertidur dengan bermimpi, atau kondisi REM (Rapid Eye Movement).

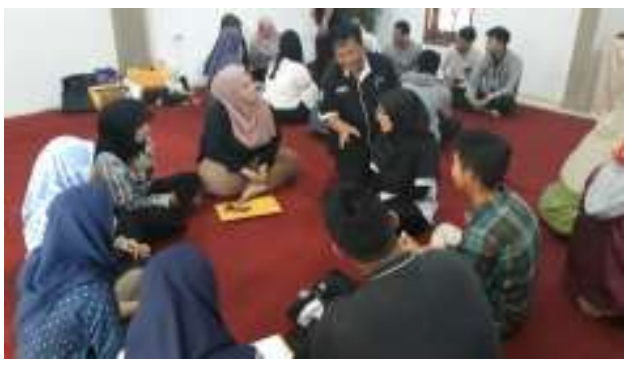

Gambar 3. Simulasi Hypnotherapy 
Frekuensi pikiran pada kondisi ini sekitar 3.5 - 7 Cps. Delta adalah kondisi tidur normal (tanpa mimpi). Frekuensi pikiran pada kondisi ini sekitar 0.5 - 3.5 Cps.

Kondisi Hypnosis sangat mirip dengan kondisi gelombang pikiran Alpha dan Theta. Yang sangat menarik, bahwa kondisi Beta, Alpha, dan Theta, merupakan kondisi umum yang berlangsung secara bergantian dalam diri kita. Suatu saat kita di kondisi Beta, kemudian sekian detik kita berpindah ke Alpha, sekian detik berpindah ke Theta, dan kembali lagi ke Beta, dan seterusnya.

Orang yang dihipnosis sebenarnya tidak dalam keadaan tidur dalam pemahaman yang sesungguhnya. Walaupun menggunakan perintah berupa kata 'tidur', kata itu tidak membuat klien tidur sesungguhnya. klien tetap dalam keadaan sadar, serta mampu mengobservasi perilakunya selama dalam keadaan hipnosis. ia menyadari segala sesuatu yang diperintahkan serta dapat menolak sesuatu yang bertentangan dengan keinginan atau norma-norma umum. Selain itu, sebelum proses ini dilakukan, telah ada kesepakatan antara klien dengan terapis untuk melakukan Hypnotherapy. (IBH, 2010).

\section{Manfaat Hipnosis}

\section{Manfaat untuk Diri Sendiri:}

Hypnosis membantu menanamkan program yang baik dan membuang program yang buruk dari diri Anda sendiri, dengan self-Hypnosis. Bisa untuk meningkatkan rasa percaya diri, lebih termotivasi, lebih fokus dalam kerja atau dalam belajar, terbebas dari kebiasaan buruk, mengembangkan potensi pikiran dan sebagainya. Intinya, Hypnosis bisa membantu diri anda untuk berubah dan berkembang menjadi lebih baik.

\section{Manfaat untuk Orang Lain:}

Anda bisa gunakan Hypnosis untuk orang lain, manfaatnya sama seperti untuk diri sendiri. Bisa untuk membantu orang lain menjadi berkembang lebih baik dan lebih maju. Tidakkah lebih indah jika kita bisa membuat orang lain menjadi lebih baik.

\section{Jika anda Orang tua:}

Hypnosis bisa digunakan untuk mendidik anak, cabang Hypnosis ini disebut HypnoParenting. Bisa digunakan untuk men-sugesti anak agar rajin belajar, menjadi lebih patuh pada orang tua, dan sebagainya.

\section{Jika anda Guru / Pengajar / Dosen:}

Metode ini disebut sebagai HypnoTeaching. HypnoTeaching adalah metode mengajar dengan Hypnosis. Jika seorang guru menguasai metode ini suasana kelas menjadi menyenangkan dan dipenuhi dengan motivasi. Akan banyak muncul generasi muda bangsa yang penuh motivasi, inspirasi dan kreatif. (Guru killer dan cara kekerasan, adalah metode kuno)

\section{Jika Anda Paramedis / Dokter:}

Hypnosis bisa digunakan untuk menghilangkan rasa sakit (anestesi) secara alami. Konon, dulu sebelum ditemukan obat bius, Hypnosis telah digunakan untuk membuat anastesi alami untuk proses pembedahan. Setelah ditemukan obat bius, maka metode hypnosis ditinggalkan, padahal anastesi dengan hypnosis tidak ada efek samping.

\section{Jika anda Psikolog atau Psikiater}

Dahulu hypnosis masuk bagian ilmu psikology, karena waktu itu teknik hypnosis masih sulit dipelajari maka metode ini ditinggalkan. Sigmund Freud, tokoh besar dalam psikologi juga awalnya menggunakan hypnosis, tapi karena sering gagal menghypnosis, maka dia meninggal hypnosis dan mengembangkan psikoanalisa. Namun sekarang ilmu Hypnosis telah 
berkembang dan jauh lebih praktis dan lebih mudah dipelajari.

\section{Jika anda Entertrainer}

Yang pasti Hypnostage akan langsung bisa membuat penonton terhibur, dengan gelak tawa, yang tadinya acaranya garing, bisa langsung ceria.

\section{Untuk Pelangsingan Tubuh:}

HypnoSlimming adalah metode pemrograman adalah mereka yang ingin langsing, dimana mereka bisa tetap makan seperti biasa, namun tubuhnya sendiri yang menyesuaikan agar tetap langsing.

\section{Untuk Meningkatkan Penjualan:}

Hypnosis ini disebut hypnoselling. Metode Hypnoselling terbagi menjadi 2, yaitu untuk sales-nya : untuk meningkatkan rasa percaya diri dan sikap mental tangguh, sehingga menjual menjadi hal yang menyenangkan baginya. Yang kedua, metode Hypnoselling adalah teknik komunikasi bagaimana mempengaruhi para prospek atau pembeli, untuk membeli dari kita.

Hypnosis secara perlahan telah menunjukkan keberadaannya seiring dengan semakin meningkatnya penerimaan pada dunia medis. Hypnosis banyak digunakan dibidang seperti pengobatan dan olahraga untuk mengubah mekanisme otak manusia dalam menginterprestasikan pengalaman dan menghasilkan perubahan pada persepsi dan tingkah laku. Aplikasi hypnosis untuk tujuan perbaikan (therapeutic) dikenal sebagai hypnotherapy.

Hypnotherapy telah terbukti memiliki beragam kegunaan untuk mengatasi berbagai permasalahan yang berkenaan dengan emosi dan perilaku. Bahkan beberapa kasus medis serius seperti kanker dan serangan jantung, hypnotherapy mempercepat pemulihan kondisi seorang penderita. Hal ini sangat dimungkinkan karena Hypnotherapy diarahkan untuk meningkatkan sistem kekebalan tubuh dan memprogram ulang penyikapan individu terhadap penyakit yang dideritanya.

Hypnosis sangat berguna dalam mengatasi beragam kasus berkenaan dengan kecemasan, ketegangan, depresi, phobia dan dapat membantu untuk menghilangkan kebiasaan buruk seperti ketergantungan pada rokok, alkohol dan obat-obatan. Dengan memberi sugesti, seseorang terapis dapat membangun berbagai kondisi emosional positif berkenaan dengan menjadi seorang bukan perokok dan penolakan terhadap rasa ataupun aroma rokok.

Khusus untuk phobia, hypnotherapy digunakan untuk mereduksi kecemasan yang mengambil alih kontrol individu atas dirinya. Hal ini dapat diwujudkan dengan menciptakan suatu gambaran nyata tentang kondisi yang menyebabkan phobia namun individu tetap dalam kondisi relax, sehingga membantu mereka untuk menyesuaikan ulang reaksi mereka pada kondisi yang menyebabkan phobia menjadi normal dan respon yang lebih tenang.

Hypnotherapy dapat digunakan untuk membawa orang mundur ke masa lampau atau Regresi kehidupan masa lalu untuk mengobati trauma dengan memberikan kesempatan untuk mengubah "fokus" perhatian.

Hypnotherapy juga dapat digunakan untuk meningkatkan optimalitas pembelajaran. Berkaitan dengan pembelajaran, hypnotherapy dapat aplikasikan untuk meningkatkan daya ingat, kreativitas, fokus, merubuhkan tembok batasan mental (self limiting mental block) dan lainnya.

\section{PENUTUP}

\section{Simpulan}

Hypnosis dan Hypnoteraphy bukanlah hal yang tabu untuk dipelajari serta bukan pula hal ghaib yang berbau magic, 
berbagai literature telah membahas bidang ilmu ini dan banyak hal positif dari mempelajari Hypnosis dan Hypnoteraphy, dengan menguasainya maka kita akan bisa mengatur alam bawah sadar kita, menghilangkan sifat-sifat buruk ataupun kebiasaan yang tidak baik, serta bisa mensugesti orang lain misalnya anak, rekan kerja dan siapapun yang membutuhkan pertolongan.

\section{Saran}

Kegiatan ini sangat berguna dalam kehidupan sehari-hari namun untuk sarana pelatihan sebaiknya menggunakan ruangan yang "tenang dan nyaman" kedap suara dan tidak terlalu sempit.

Kegiatan selanjutnya tim pengambdian kepada masyarakat akan melakukan pelatihan hypnoteaching untuk para pengajar dan hypnomotivasi untuk para pelajar.

\section{Ucapan Terima Kasih}

Tim pelaksana pengabdian kepada masyarakat mengucapkan terimakasih kepada (LPPM) Lembaga Penelitian Dan Pengabdian Kepada Masyarakat Universitas Pamulang Tangerang Selatan, Lembaga Penelitian Dan Pengabdian Kepada Masyarakat (STIKES) Sekolah Tinggi Ilmu Kesehatan Jenderal Achmad Yani Cimahi serta rekan dosen dan para mahasiswa.

\section{E. DAFTAR PUSTAKA}

Gunawan, A. W. (2012). Hypnotherapy The Art of Subconscious Restructuring: PT Gramedia Pustaka Utama.

IBH. (2010). Modul Fundamental Hipnoterapi Workshop. Jakarta: The Indonesian Board of Hypnotherapy (IBH).
Kahija. (2017). Hipnoterapi: Prinsip-prinsip dasar praktek psikoterapi. Jakarta: Gramedia Pustaka Utama.

Hajar, I. (2012). Hypnoteaching. Memaksimalkan Hasil Proses BelajarMengajar Dengan Hipnoterapi. Yogyakarta: DIVA Press.

Hakim, A. (2011). Dahsyatnya Pikiran Bawah Sadar: VisiMedia.

Roswendi, A. S., \& Sunarsi, D. (2020). Dinamika dan Perkembangan Hypnotherapy Dalam Perspektif Interdisipliner. Cilegon: Runzune Sapta Konsultan

Roswendi, A. S. (2019). Hypnomotivation Effect To Decrease Dependence Attitude On Drug Addicts In Rehabilitation Centers Of Social Pamardi Putra Lembang West Bandung. In The 3rd International Seminar on Global Health (Vol. 3, No. 1, pp. 206-211).

Roswendi, A. S., \& Nabila, S. L. (2017). The Influence of Group Guidance using Home Room Technique on Anxiety Level of Young Women Who Confonted by Menacrhe Grade IV, V, in Aisyiah Islamic Center Elementary School Cianjur. In Proceeding International Seminar on Global Health (ISGH) 2017 (Vol. 1, No. 1, pp. 264-270).

Sunarsi, D. (2019). The Analysis of The Work Environmental and Organizational Cultural Impact on The Performance and Implication of The Work Satisfaction. Jurnal Ilmiah Ilmu Administrasi Publik, 9(2), 113122.

Sunarsi, D. (2018). Pengaruh Motivasi Dan Disiplin Terhadap Produktivitas Kerja 
Karyawan Pada PT. Nadi Suwarna Bumi. Jurnal Semarak, 1(1).

Sunarsi, D. (2018). Analisis Motivasi Kerja Tenaga Pendidik Sukarela Pada Pusat Kegiatan Belajar Masyarakat (PKBM) Bimasda Kota Tangerang Selatan. Kreatif: Jurnal Ilmiah Prodi Manajemen Universitas Pamulang, 6(2), 53-65.

Sunarsi, D. (2020). Panduan Meningkatkan Kinerja Dan Kepuasan Guru. Kota Serang: Desanta Muliavisitama. 